\title{
Emotional Attitudes of Chinese Citizens on Social Distancing During the COVID-19 Outbreak: Analysis of Social Media Data
}

Lining Shen ${ }^{1,2,3^{*}}$, PhD; Rui Yao ${ }^{1 *}$, MS; Wenli Zhang ${ }^{1}$, MS; Richard Evans ${ }^{4}$, PhD; Guang Cao ${ }^{1}$, MS; Zhiguo Zhang ${ }^{1,2}$, $\mathrm{PhD}$

\footnotetext{
${ }^{1}$ School of Medicine and Health Management, Tongji Medical College, Huazhong University of Science \& Technology, Wuhan, China

${ }^{2}$ Hubei Provincial Research Center for Health Technology Assessment, Wuhan, China

${ }^{3}$ Institute of Smart Health, Huazhong University of Science \& Technology, Wuhan, China

${ }^{4}$ College of Engineering, Design and Physical Sciences, Brunel University London, London, United Kingdom

*these authors contributed equally
}

\section{Corresponding Author:}

Lining Shen, PhD

School of Medicine and Health Management

Tongji Medical College

Huazhong University of Science \& Technology

No 13 Hangkong Road

Wuhan, 430030

China

Phone: 8602783692730

Email: $\underline{\sin 2008 @ \text { hust.edu.cn }}$

\begin{abstract}
Background: Wuhan, China, the epicenter of the COVID-19 pandemic, imposed citywide lockdown measures on January 23, 2020. Neighboring cities in Hubei Province followed suit with the government enforcing social distancing measures to restrict the spread of the disease throughout the province. Few studies have examined the emotional attitudes of citizens as expressed on social media toward the imposed social distancing measures and the factors that affected their emotions.

Objective: The aim of this study was twofold. First, we aimed to detect the emotional attitudes of different groups of users on Sina Weibo toward the social distancing measures imposed by the People's Government of Hubei Province. Second, the influencing factors of their emotions, as well as the impact of the imposed measures on users' emotions, was studied.

Methods: Sina Weibo, one of China's largest social media platforms, was chosen as the primary data source. The time span of selected data was from January 21, 2020, to March 24, 2020, while analysis was completed in late June 2020. Bi-directional long short-term memory (Bi-LSTM) was used to analyze users' emotions, while logistic regression analysis was employed to explore the influence of explanatory variables on users' emotions, such as age and spatial location. Further, the moderating effects of social distancing measures on the relationship between user characteristics and users' emotions were assessed by observing the interaction effects between the measures and explanatory variables.
\end{abstract}

Results: Based on the 63,169 comments obtained, we identified six topics of discussion-(1) delaying the resumption of work and school, (2) travel restrictions, (3) traffic restrictions, (4) extending the Lunar New Year holiday, (5) closing public spaces, and (6) community containment. There was no multicollinearity in the data during statistical analysis; the Hosmer-Lemeshow goodness-of-fit was $0.24\left(\chi_{8}^{2}=10.34, P>.24\right)$. The main emotions shown by citizens were negative, including anger and fear. Users located in Hubei Province showed the highest amount of negative emotions in Mainland China. There are statistically significant differences in the distribution of emotional polarity between social distancing measures $\left(\chi_{20}^{2}=19,084.73, P<.001\right)$, as well as emotional polarity between genders $\left(\chi_{4}^{2}=1784.59, P<.001\right)$ and emotional polarity between spatial locations $\left(\chi_{4}^{2}=1659.67\right.$, $P<.001)$. Compared with other types of social distancing measures, the measures of delaying the resumption of work and school or travel restrictions mainly had a positive moderating effect on public emotion, while traffic restrictions or community containment had a negative moderating effect on public emotion.

Conclusions: Findings provide a reference point for the adoption of epidemic prevention and control measures, and are considered helpful for government agencies to take timely actions to alleviate negative emotions during public health emergencies. 
(JMIR Med Inform 2021;9(3):e27079) doi: 10.2196/27079

\section{KEYWORDS}

COVID-19; Sina Weibo; social distancing measures; emotional analysis; machine learning; moderating effects; deep learning; social media; emotion; attitude; infodemiology; infoveillance

\section{Introduction}

\section{Background}

In late 2019, COVID-19 began to spread rapidly throughout Hubei Province, China, creating devastating consequences for citizens and organizations and heavily burdening the provision of public health care in the province. The unknown pneumonia strain led to a major public health emergency; it has been deemed to be the disease with the fastest transmission rate, the greatest infection rate, and the most difficult to prevent since the establishment of New China [1]. The World Health Organization declared COVID-19 a public health emergency of international concern on January 31, 2020, and a pandemic on March 11, 2020 [2]. To prevent further outbreaks and disease transmission, the Chinese government adopted a series of measures to restrict the transmission and infection of the disease during the Lunar New Year holiday [3]. Although the 2020 Chinese Lunar New Year holiday is from January 24-31, 2020, to prevent and control the epidemic, the General Office of the State Council extended the holiday to February 2, 2020. At the epicenter of the epidemic, the People's Government of Hubei Province extended the holiday to February 13, 2020. The most widely imposed measure was to increase physical distancing between people [4], including traffic restrictions [5], delaying the resumption of work and school [6], extending the Lunar New Year holiday [7], travel restrictions [8], and community containment and closing of public spaces [9]. Such measures that aim to reduce exposure to the disease, by reducing contact between people, is known as "social distancing" [10]. The United States Centers for Disease Control and Prevention defined social distancing as the restriction of close face-to-face contact with others and considers it the best method for reducing the spread of COVID-19 [11].

Since the advent of the internet, social media has become an indispensable part of citizens' lives, greatly enriching the way people share feelings and exchange opinions. As of October 2020, there were approximately 4.66 billion active internet users worldwide, including 4.14 billion active social media users, accounting for $59 \%$ and $51 \%$ of the global population, respectively [12]. According to the 46th China Statistical Report on Internet Development, revised in June 2020, the number of Chinese internet users has reached 940 million [13]. International social media users tend to express their opinions on Twitter, due to its quick release and acceptance of information [14]. As an alternative to Twitter in Mainland China, Sina Weibo [15] has played an important role during many public health emergencies in recent years [16]. Studies have shown that through the analysis of content published on social media platforms, citizens' views and attitudes toward an event can be tracked and discovered [17,18]. During the COVID-19 pandemic, netizens expressed significant views on the imposed social distancing measures for disease prevention and control in Hubei Province. Through the collection of text related to social distancing on the internet, we can gain a better understanding of Sina Weibo users' emotional attitudes toward the imposed measures, so as to provide data for government agencies to implement measures in a timely fashion.

\section{Related Work}

\section{Social Distancing During Public Health Emergencies}

In public health emergencies, social distancing has become an important course of action to prevent the spread of diseases. For example, social distancing measures imposed during the influenza pandemic drastically reduced the infection rate $[19,20]$. One study into the severe acute respiratory syndrome (SARS) epidemic found that the prevention and control of the epidemic, through the implementation of social distancing measures, had a certain effect in Canada [21]. During the COVID-19 pandemic, government agencies have also encouraged the adoption of social distancing measures. Zhang et al [22] studied the impact of social distancing measures on the spread of COVID-19 by establishing a disease transmission model. Other studies have confirmed that by closing schools and universities, there has been a significant reduction in the spread of the disease [23-25]. Self-quarantine measures also helped reduce the transmission rates of influenza in Texas in 2009, as well as for SARS in Singapore in 2003 [26,27]. The sanitary cordon helped set back an epidemic of Ebola in 1995 in the city of Kikwit, Zaire [28]. Workplace social distancing guidelines delayed and reduced the peak influenza attack rate [29]. In addition, travel restrictions and the canceling of mass gatherings have also been effective strategies for reducing the burden of COVID-19 on health care providers [30,31].

However, the use of social distancing measures by local governments during the COVID-19 pandemic may have a negative impact on citizens' mental health and well-being $[32,33]$. Therefore, it is important to study the psychology of citizens and their behaviors in the context of social distancing measures.

\section{Emotional Expression During Public Health Emergencies}

Emotional polarity analysis is often used to examine the emotional tendencies expressed in text and to discover the emotional attitudes of users. Some studies have found that the pandemic has led to negative emotions being expressed by internet users [34,35]. For example, Ogoina et al [36] found that health care workers demonstrated varying degrees of fear related to the Ebola epidemic in Nigeria in 2014, through self-administered questionnaires and documented observations. Other scholars have explored the emotional attitudes of citizens toward epidemic diseases through questionnaires [37,38]. However, all studies have only explored the change in citizens' 
emotions through cross-sectional data, and the samples examined were not large.

As an important medium for public communication, social media provides a large-scale corpus for emotional analysis. Emotion lexicons and machine learning are two methods commonly used for analytical analysis. In terms of emotion lexicons, there are relatively mature lexical resources available, such as SentiWordNet and the National Research Council of Canada (NRC) word-emotion lexicon [39,40]. Das et al [41] used the NRC word-emotion lexicon to analyze the emotions of Twitter users about COVID-19 in India. In the field of machine learning, Du et al [42] used a convolutional neural network (CNN) classifier to conduct an emotional analysis on Twitter data during the measles outbreak. Ji et al [43] also found that multinomial naive Bayes (NB) was effective in analyzing the emotion of Twitter users facing epidemics. Although a classification method based on emotion lexicons is effective, it relies heavily on the scale and frequency of updating the lexicon, while a classification method based on machine learning avoids this limitation and is widely used today. For example, Behera et al [44] studied the emotional classification of tweets related to three diseases-malaria, swine flu, and cancer-through emotion lexicon and NB methods. Their results showed that the performance of the NB algorithm was better than that of the emotion lexicon.

\section{Objectives}

Social distancing measures are essential for controlling the spread of infectious diseases during pandemics. However, based on existing research, it is evident that current studies into social distancing have mainly focused on the impact of social distancing measures on the spread of infection rates and mortality. To date, there are few studies that have explored citizens' emotions related to specific social distancing measures. By detecting the emotional attitudes of Sina Weibo users toward the imposed social distancing measures adopted by Hubei Province, the epicenter of the COVID-19 outbreak in Mainland China, government agencies can take timely action to calm citizens' emotions. In this study, the following four research questions (RQs) are identified:

- RQ1: what were the emotional attitudes of Sina Weibo users toward the various social distancing measures imposed by Hubei Province?
- RQ2: what were the changing trends in Sina Weibo users' emotions over time?

- RQ3: what was the impact of user characteristics of social media on their emotions?

- RQ4: what was the moderating effect of social distancing measures on the relationship between the explanatory variables and the explained variable?

\section{Methods}

\section{Data Collection and Preprocessing}

Due to the severity of the COVID-19 outbreak in Hubei Province, the government of Hubei Province issued the "Notice of the People's Government of Hubei Province on strengthening the prevention and control of the new coronavirus pneumonia" on January 21, 2020 [45], which stipulated strict restrictions against large-scale activities and personal movement; this led to the successful employment of social distancing measures to reduce the risk of infection among citizens. Subsequently, due to improvements in the epidemic situation, the government of Hubei Province announced on March 24, 2020, that it would gradually lift restrictions in the province. Therefore, the time span of the selected data in this study range from January 21 to March 24, 2020.

In addition, since Sina Weibo has gradually become the main social media platform for Chinese citizens, this study selected this platform as the data source. After combing hashtags on Sina Weibo, which is an efficient method for identifying trending topics [46], a total of 34 hashtags related to social distancing measures adopted by Hubei Province were identified. These hashtags were then categorized under the six social distancing measures, as shown in Table 1. To ensure data quality, comments about posts published by the official news channels of government agencies, certified by the Sina Weibo platform, were crawled using Python 3.7, retrieving a total of 67,304 comments published by 58,996 netizens. After removing duplicate data and comments without textual expression, 63,169 comments were identified. The main data collected included username, gender, spatial location, account registration year, and comment content. The process of subsequent analysis is shown in Figure 1. 
Table 1. Hashtags on social distancing measures related to COVID-19 on Sina Weibo.

\begin{tabular}{|c|c|}
\hline Measures categories & Hashtags \\
\hline Delaying the resumption of work and school & $\begin{array}{l}\text { - } \quad \text { \#The start of the school year for Hubei elementary and middle schools has been postponed\# } \\
\text { - } \quad \text { \#Colleges and universities in Hubei have postponed the start of classes\# } \\
\text { - } \quad \text { \#Schools in Hubei have postponed the start of the school year\# } \\
\text { - } \quad \text { \#Hubei has postponed the start of school\# } \\
\text { - } \quad \text { \#Tubei continues to delay the resumption of work and school\# } \\
\text { - } \quad \text { \#Hubei continues to delay the start of school\# } \\
\text { - } \quad \text { \#Hubei issued a notice to continue to delay the resumption of work and schools\# } \\
\text { - } \quad \text { \#Various enterprises in Hubei will resume work no earlier than 24:00 on February 20\# } \\
\text { - } \quad \text { \#Enterprises in Hubei Province will resume work no earlier than 24:00 on March 10\# }\end{array}$ \\
\hline Travel restrictions & $\begin{array}{l}\text { - } \quad \text { \#Wuhan canceled all tour groups\# } \\
\text { - } \quad \text { \#All tour groups in Wuhan will be cancelled\# } \\
\text { - } \quad \text { \#Hubei travel agencies have suspended business activities\# } \\
\text { - } \quad \text { \#ubei province has suspended the operations of travel agencies across the province\# }\end{array}$ \\
\hline Traffic restrictions & $\begin{array}{l}\text { - } \quad \text { \#Wuhan's public transportation and subway operations have been suspended\# } \\
\text { - } \quad \text { \#Buses and subways in Wuhan were suspended\# } \\
\text { - } \quad \text { \#Traffic in Wuhan was suspended\# } \\
\text { - } \quad \text { \#Long-distance passenger transportation of Wuhan bus, subway and ferry will be suspended from } \\
\text { the 23rd\# } \\
\text { - } \quad \text { \#The Wuanan exit route was temporarily closed\# } \\
\text { - } \quad \text { \#Wuhan airport, railway station, and other exit routes were temporarily closed\# } \\
\text { - } \quad \text { \#Wuhan closed the river-crossing tunnel\# }\end{array}$ \\
\hline Extending the Lunar New Year holiday & $\begin{array}{l}\text { - } \quad \text { \#The Spring Festival holiday was extended to February 2\# } \\
\text { - } \quad \text { \#Hubei Province will appropriately extend the Spring Festival holiday\# } \\
\text { - } \quad \text { \#Hubei Province extended the Spring Festival holiday until February 13\# }\end{array}$ \\
\hline Closing public spaces & $\begin{array}{l}\text { - } \quad \text { \#Cinemas throughout Wuhan were temporarily closed\# } \\
\text { - } \quad \text { \#Wuhan cultural and entertainment venues were temporarily closed\# } \\
\text { - } \quad \text { \#All star hotel activities in A-level scenic spots in Hubei Province will be cancelled\# } \\
\text { - } \quad \text { All non-essential public places in Hubei were closed\# }\end{array}$ \\
\hline Community containment & $\begin{array}{l}\text { - } \quad \text { \#Communities in Hubei Province are under closed management\# } \\
\text { - } \quad \text { \#All residential communities in Wuhan are under closed management\# } \\
\text { - } \quad \text { \#Whan community adopted closed management\# } \\
\text { - } \quad \text { \#The communities in Hubei Province are most strictly closed } 24 \text { hours a day\# } \\
\text { - } \quad \text { \#The closed management of villages and community in the Wuhan will continue } 24 \text { hours a day\# }\end{array}$ \\
\hline
\end{tabular}


Figure 1. Flowchart for obtaining data from Sina Weibo for subsequent analysis.

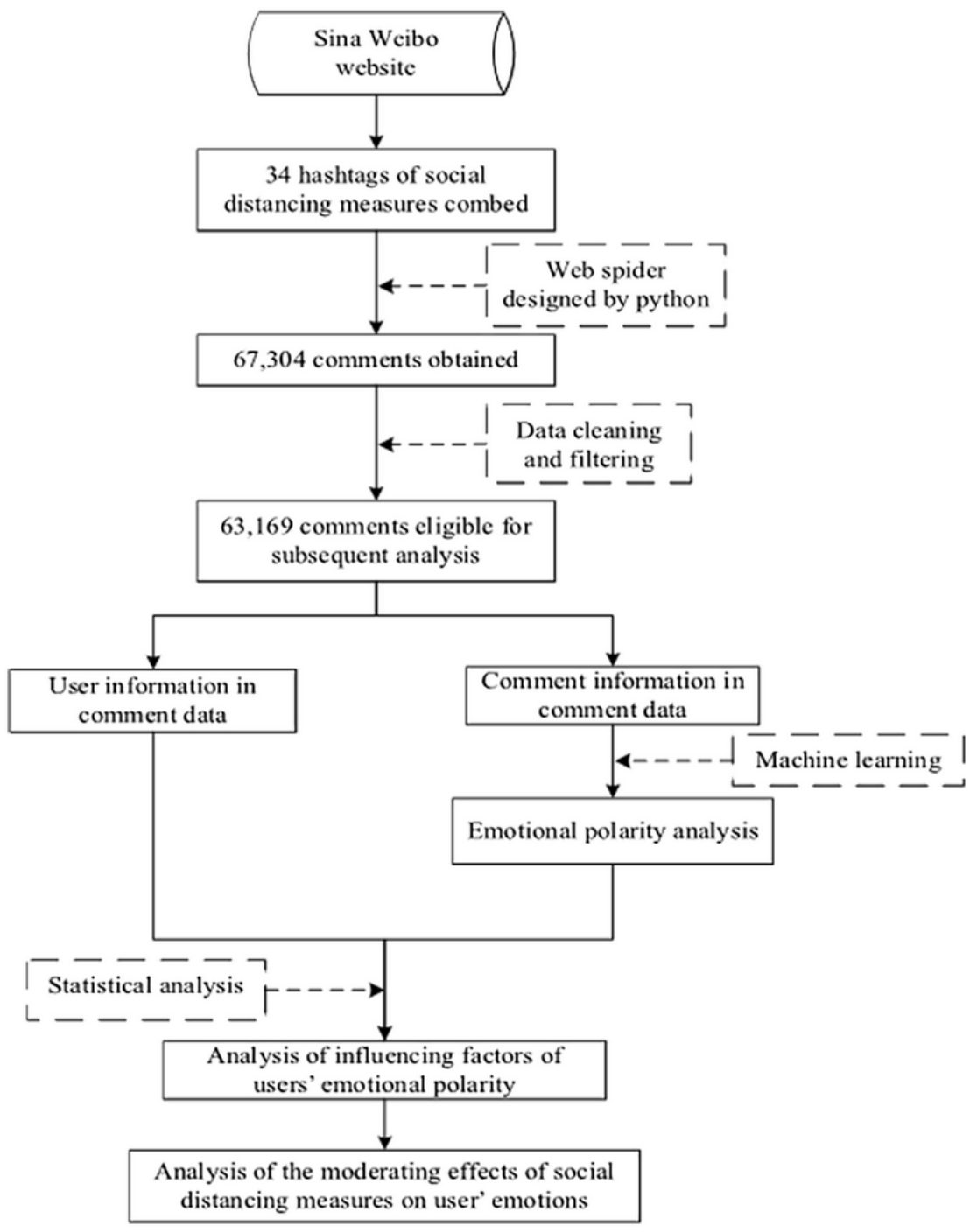

\section{Emotional Polarity Analysis}

Since the introduction of text sentiment analysis in 2008, machine learning methods have achieved consistently good results $[47,48]$. Therefore, we chose machine learning algorithms to perform emotional analysis on the corpus.

First, corpora marking was completed. The current research on emotional analysis mainly divides emotional types into three or five categories [49,50]. In addition, the Ortony-Clore-Collins (OCC) model, proposed by Ortony et al [51] in 1988, is a refined emotion classification model that offers a rule-based emotion export mechanism, which has been widely applied to studies that examine emotion classification of social media users [52]. Based on the three evaluation criteria of the OCC model, consequences of events, action of agents, and aspects of objects, as well as different intensities or inducing causes, this study constructed "anger," "fear," "neutral," "encouragement," and "hope" emotions to analyze Sina Weibo users' emotions. The emotions of "anger" and "encouragement" are related to the action of agents, emotions of "fear" and "hope" are related to the consequences of events, and neutral emotions indicate objective facts. Then, according to the above rules of emotion classification, we programed in Python; the first and second authors used traditional labeling methods to label the corpus [53]. We randomly chose more than 5000 corpora and marked them with one of the five emotional polarity. Then, the Kappa coefficient was used to evaluate the consistency of the corpus marking [54]. The Kappa value was $0.95(P<.01)$, indicating that the marked corpora had strong consistency [55].

We then predicted the emotional polarity of the comments collected. First, we selected four representative training classifiers of machine learning algorithms: support vector machine (SVM), convolutional neural networks (CNN), long short-term memory (LSTM), and bi-directional long short-term memory (Bi-LSTM). Based on the marked corpora, we divided them into training sets, validation sets, and test sets, according to a 6:2:2 ratio, and then input them into different classifier models for testing. These tests were carried out in September 2020. Three indicators-precision, recall, and F1-score-were used for the model evaluation [56]. The precision rate reflects the ability of the classifier to determine the whole sample; the recall rate intuitively reflects the proportion of positive samples that are correctly identified; and the F1-score can be interpreted as a weighted average of precision and recall. As shown in Table 2, the Bi-LSTM classifier exhibited the best performance for testing emotional polarity for the remaining corpora [57]. 
Subsequently, the Bi-LSTM classifier was used to predict the emotional polarity of all corpora, and this process was performed

using Python.

Table 2. The performance of the emotional polarity classification model.

\begin{tabular}{llll}
\hline Model & Precision & Recall & F1-score \\
\hline SVM $^{\mathrm{a}}$ & 0.512 & 0.506 & 0.509 \\
$\mathrm{CNN}^{\mathrm{b}}$ & 0.619 & 0.602 & 0.607 \\
LSTM $^{\mathrm{c}}$ & 0.664 & 0.664 & 0.658 \\
Bi-LSTM $^{\mathrm{d}}$ & 0.701 & 0.699 & 0.701 \\
\hline
\end{tabular}

${ }^{\mathrm{a}} \mathrm{SVM}$ : support vector machine.

${ }^{\mathrm{b}} \mathrm{CNN}$ : convolutional neural network.

${ }^{\mathrm{c}}$ LSTM: long short-term memory.

${ }^{\mathrm{d}}$ Bi-LSTM: bidirectional long short-term memory.

\section{Research Hypotheses and Statistical Analysis}

\section{Theoretical Background and Hypotheses Design}

To study the emotional attitudes of Sina Weibo users, we examined the impact of user characteristics and social distancing measures on the emotional tendency of users. We then proposed hypotheses.

First, according to the Media Dependency Theory [58], the effects of the media are due to the media meeting the needs of specific audiences in a specific way in a specific society. Obviously, audiences' use of media platforms determines the media's influence, namely, personal media dependence depends on personal factors [59]. Therefore, based on the Media Dependence Theory and the data collected on Sina Weibo users, this study hypothesizes that users' age, spatial location, and social media registration year affects their emotional expression $[60,61]$. Accordingly, we proposed the following hypotheses:

- H1a: the age of Sina Weibo users has a significant impact on their emotional expression;

- H1b: the spatial location of Sina Weibo users has a significant impact on their emotional expression;

- H1c: the registration year of Sina Weibo users has a significant impact on their emotional expression.

Second, according to the Risk Information Seeking and Processing Model, proposed by Griffin [62], relevant channel beliefs affect individuals' information processing methods differently [63]. In addition, the 5W Theory (Who, When, Where, What, and How), proposed by Lasswell [64], reveals the communication elements in the communication process. Among them, the first element "who" is played by different types of users on the Sina Weibo platform [65-67]. Therefore, this study measured the emotional response of different user characteristics from the perspective of social media, and proposed the following hypotheses:

- H2a: the number of fans of Sina Weibo users has a significant impact on their emotional expression;

- H2b: the number of follows of Sina Weibo users has a significant impact on their emotional expression;
- H2c: the number of posts shared by Sina Weibo users has a significant impact on their emotional expression.

Third, the Agenda-Setting Theory, formally proposed by McCombs and Shaw [68], posits that mass media can effectively influence users' attention to certain facts by providing information and arranging related issues. The theory further discusses that records of public discussion on public affairs can be obtained from social media for observation and analysis $[69,70]$. Based on this theory, we discussed the impact of different social distancing measures on the emotional expression of different types of Sina Weibo users, and proposed the following hypothesis:

- H3: The categories of social distancing measures have a moderating effect on the relationship between the user characteristics of different types of Sina Weibo users and their emotions.

\section{Statistical Analysis of Influencing Factors of Emotional Polarity}

Based on the above hypotheses, we selected the factors that affect users' emotions for statistical analysis. Given that the P value of the test of parallel lines is less than .001, we analyzed the factors that influence Sina Weibo users' emotions using multinomial logistic regression, performed by SPSS 21.0 (IBM Corp); our variables are shown in Table 3. Among the variables, based on the existing research results [71], gender was set as the control variable. Based on related data [72,73], the spatial locations of Sina Weibo users were divided into Hubei Province, emigrant provinces with the largest population influx from Hubei Province before the Wuhan lockdown (including Guangdong, Beijing, Shanghai, Henan, Anhui, Jiangxi, Sichuan, Hunan, and Chongqing), and other provinces. In addition, the effects of various explanatory variables on anger and fear emotions, as well as hope and encouragement emotions, are consistent. Therefore, we merged the five categories of emotions into three categories (positive, neutral, and negative) for statistical analysis. Further, the moderator variables included the six categories of social distancing measures adopted by Hubei Province. In the subsequent analysis, each category was set as the reference group to observe the interaction effect between it and the explanatory variables, which can judge the 
moderating effect of social distancing measures [74]. From the above, we established the following model:

$$
\begin{aligned}
& \operatorname{Logit}\left(P \_ \text {Emo }\right)=\beta_{0}+\beta_{1} \text { Sex }+\beta_{2} \text { Age }+\beta_{3} \text { Space } 1+ \\
& \beta_{4} \text { Space } 2+\beta_{5} \operatorname{Ln}\left(N_{-} \text {Fan }\right)+\beta_{6} \operatorname{Ln}\left(N_{-} \text {Follow }\right)+
\end{aligned}
$$

$$
\begin{aligned}
& \beta_{7} \operatorname{Ln}\left(N \_ \text {Post }\right)+\beta_{8} \text { Time_Reg }+\beta_{9} T \_S D M+\beta_{10} \text { Age } \\
& \times T \_S D M+\beta_{11} \text { Space } 1 \times T \_S D M+\beta_{12} S p a c e 2 \times \\
& T \_S D M+\beta_{13} L n\left(N \_F a n\right) \times T \_S D M+ \\
& \beta_{14} L n\left(N \_F o l l o w\right) \times T \_S D M+\beta_{15} L n\left(N \_P o s t\right) \times \\
& T \_S D M+\beta_{16} \text { Time_Reg } \times T \_S D M+\varepsilon
\end{aligned}
$$

\begin{tabular}{|c|c|c|}
\hline Variable & Variable symbol & Description and coding \\
\hline \multicolumn{3}{|l|}{ Explained variable } \\
\hline Emotional polarity & P_Emo & Sina Weibo users' emotional polarity \\
\hline \multicolumn{3}{|l|}{ Control variable } \\
\hline Sex & Sex & $\begin{array}{l}\text { The sex of Sina Weibo users. The coding is as follows: } \\
0=\text { female and } 1=\text { male (reference group) }\end{array}$ \\
\hline \multicolumn{3}{|l|}{ Explanatory variables } \\
\hline Age & Age & The age of Sina Weibo users (range 16-65 years) \\
\hline Spatial location & Space1, Space2 & $\begin{array}{l}\text { The spatial locations of Sina Weibo users. We used } \\
\text { "other provinces" as the reference group. The dummy } \\
\text { variables are as follows: } \\
\text { - } \quad \text { Space } 0=\{\text { other provinces, when Space } 1=0 \text { and } \\
\text { Space } 2=0\} \text { (reference group) } \\
\text { - Space } 1=\{1=\text { Hubei Province; } 0=\text { others }\} \\
\text { - } \quad \text { Space } 2=\{1=\text { emigrant provinces; } 0=\text { others }\}\end{array}$ \\
\hline Number of fans & Ln(N_Fan) & $\begin{array}{l}\text { The number of fans of Sina Weibo users; smoothed } \\
\text { logarithmically }\end{array}$ \\
\hline Number of follows & Ln(N_Follow) & $\begin{array}{l}\text { The number of other users that Sina Weibo users fol- } \\
\text { low; smoothed logarithmically }\end{array}$ \\
\hline Number of post & Ln(N_Post) & $\begin{array}{l}\text { The number of posts shared by Sina Weibo users; } \\
\text { smoothed logarithmically }\end{array}$ \\
\hline Registration year & Time_Reg & The registration year of Sina Weibo users' accounts \\
\hline \multicolumn{3}{|l|}{ Moderator variable } \\
\hline Social distancing measures & T_SDM & $\begin{array}{l}\text { The types of social distancing measures. The coding } \\
\text { is listed as follows: } \\
\text { - } \quad \text { SDM1=delaying the resumption of work and } \\
\text { school } \\
\text { - } \quad \text { SDM2=travel restrictions } \\
\text { - } \quad \text { SDM3= traffic restrictions } \\
\text { - } \quad \text { SDM4=closing public spaces } \\
\text { - } \quad \text { SDM5=community containment } \\
\text { - } \quad \text { SDM6=extending the Lunar New Year holiday } \\
\text { (reference group) }\end{array}$ \\
\hline
\end{tabular}

Table 3. Description of variables that influence Sina Weibo users' emotions.

In total, 21,395 comments were identified for statistical analysis after removing some records with missing age, since disclosing age is not required for user registration.

\section{Results}

\section{Basic Description of Comments and Users' Emotional Polarities}

\section{Distribution of Comments}

From January 21 to March 24, 2020, Sina Weibo users discussed the social distancing measures imposed by the People's
Government of Hubei Province. The three measures of traffic restrictions, community containment, and delaying the resumption of work and school attracted high attention from users, while travel restrictions, extending the Lunar New Year holiday, and closing public places attracted less attention; further details are shown in Figure 2. 
Figure 2. Proportion of comments related to each social distancing measure $(\mathrm{N}=63,169)$.

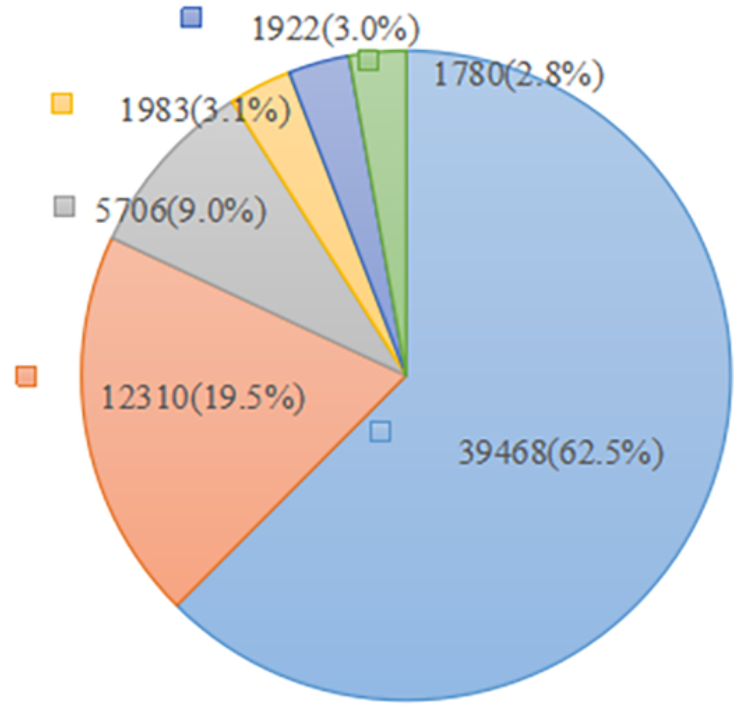

Traffic restrictions

Community containment

Delaying the resumption of

work and school

$\square$ Extending the Lunar New

Year holiday

$\square$ Travel restrictions

Closing public spaces
To analyze the data of various provinces in China, the data of users registered as "other" and "overseas" were removed, yielding 46,431 comments. Local netizens in Hubei Province paid the greatest attention to social distancing measures, followed by those residing in the Guangdong, Beijing, and
Shanghai. These are areas where citizens from Hubei Province relocated to before the lockdown was imposed in Wuhan City. The number of comments from users in other provinces was relatively small, as shown in Figure 3.

Figure 3. Spatial distribution of comments from Sina Weibo users $(\mathrm{N}=46,431)$.

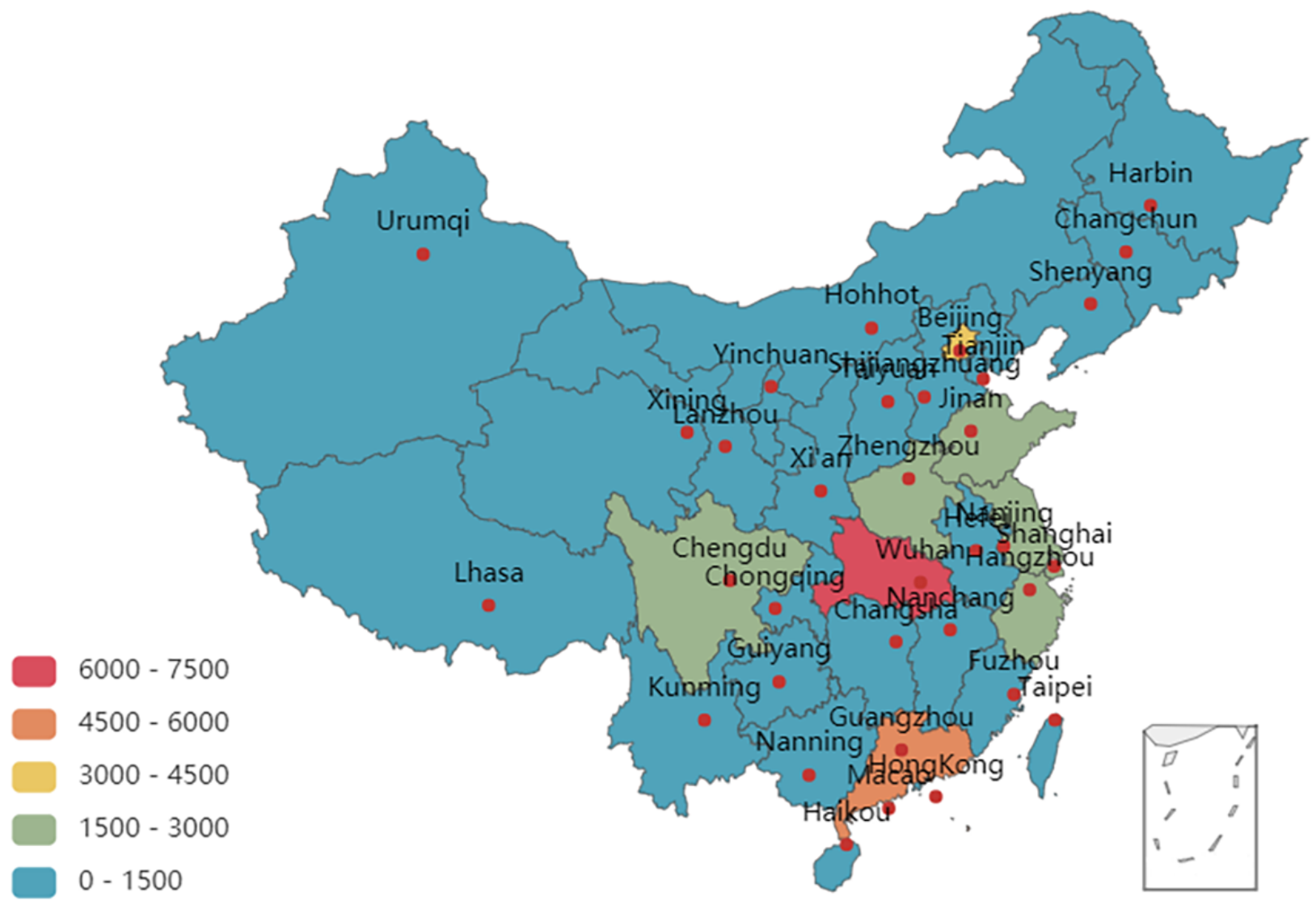


Distribution of Users' Emotional Polarity Across Gender

The findings show that women held a higher proportion of positive emotions than men (Table 4). Further, the chi-square test result $\left(\chi_{4}^{2}=1784.59, P<.001\right)$ shows that the emotional expression of different genders varied.

Table 4. Proportion of users' emotional polarities across different genders ( $\mathrm{N}=63,169)$.

\begin{tabular}{|c|c|c|c|c|c|}
\hline \multirow[t]{2}{*}{ Sex } & \multicolumn{2}{|l|}{ Positive } & \multirow[t]{2}{*}{ Neutral } & \multicolumn{2}{|l|}{ Negative } \\
\hline & Hope & Encouragement & & Fear & Anger \\
\hline Male (n=19,016), n (\%) & $1512(8.0)$ & $4505(23.7)$ & $2896(15.2)$ & 4467 (23.5) & $5636(29.6)$ \\
\hline Female $(\mathrm{n}=44,153), \mathrm{n}(\%)$ & $4383(9.9)$ & $16,936(38.4)$ & $4207(9.5)$ & $9601(21.7)$ & $9026(20.4)$ \\
\hline
\end{tabular}

\section{Distribution of Emotional Polarity Among Users From Different Spatial Locations}

As shown in Figure 4, for users in Hubei Province, the proportion of negative emotions $(4605 / 7291,63.2 \%)$ is significantly different from that of positive emotions (1545/7291, 21.2\%). Sina Weibo users in Hubei Province showed the least amount of positive emotions while residents of emigrant provinces expressed the most positive emotions. There was little difference between the emigrant provinces and other provinces, but the proportion of negative emotions was slightly lower than that of other provinces. In addition, the chi-square test result $\left(\chi_{4}^{2}=1659.67, P<.001\right)$ shows that the emotional expression of users in different spatial locations is indeed different.

Figure 4. Proportion of users' emotional polarity from different spatial locations $(\mathrm{N}=63,169)$.

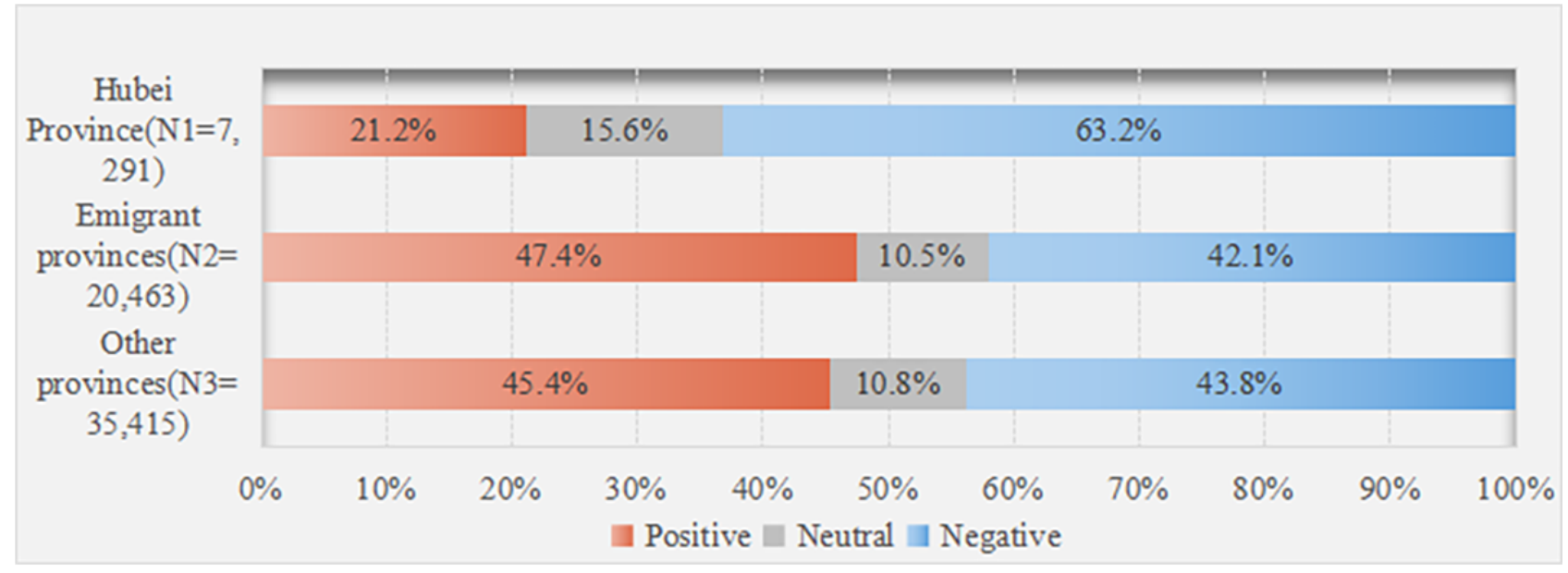

\section{Evolution of Emotional Polarity}

\section{Distribution of Users' Emotional Polarity Based on Different Social Distancing Measures}

Except for the measure of traffic restrictions, netizens' emotions regarding the other five measures were all negatively inclined (Figure 5). Specifically, for the measure of traffic restrictions, netizens' positive emotions make up the largest proportion $(24,143 / 39,468,61.2 \%)$ among all the measures. For delaying the resumption of work and school, netizens mostly expressed negative emotions (4129/5706, 72.4\%), such as fear and anger. For travel restrictions, emotions surrounding hope accounted for the highest proportion $(472 / 1922,15.6 \%)$. In terms of extending the Lunar New Year holiday, closing public spaces, and community containment, negative emotions accounted for a high proportion of total comments. For community containment, anger was expressed more frequently compared to all other measures. The chi-square test result $\left(\chi_{20}^{2}=19,084.73\right.$, $P<.001)$ showed that Sina Weibo users have varying emotional expressions for different topics. 
Figure 5. Distribution of users' emotional polarity under various social distancing measures $(N=63,169)$.

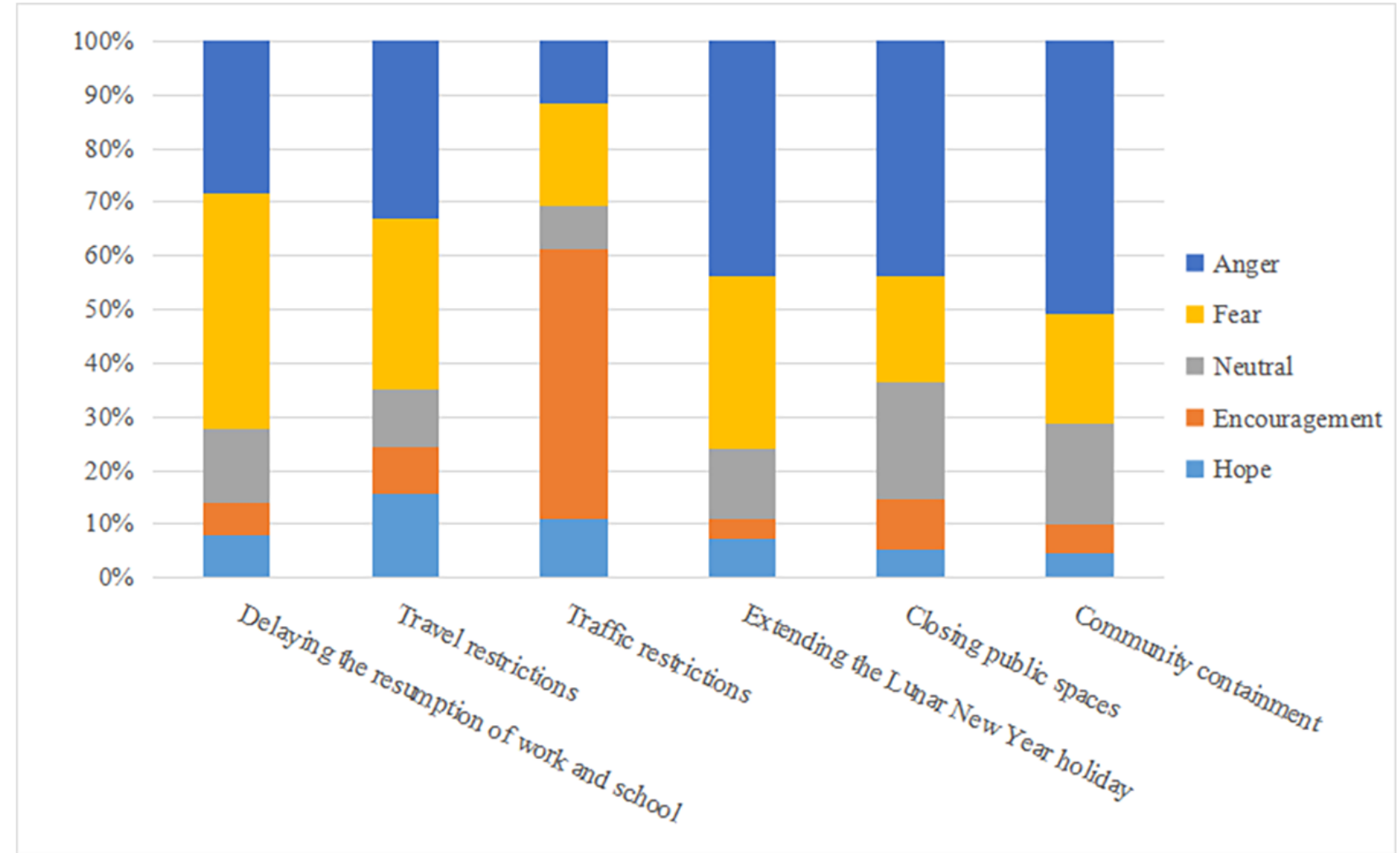

\section{Evolution Process of Users' Emotional Polarity Over Time}

As shown in Figure 6, on January 23, 2020, when the city of Wuhan was locked down, users showed a high degree of encouragement. However, since January 24, 2020, negative emotions gradually increased with users expressing fear and anger toward the imposed social distancing measures employed by Hubei Province. Then, after January 27, 2020, users' negative emotions centered on anger toward the social distancing measures imposed in Hubei Province.

Figure 6. Evolution process of emotional polarity over time $(\mathrm{N}=63,169)$.

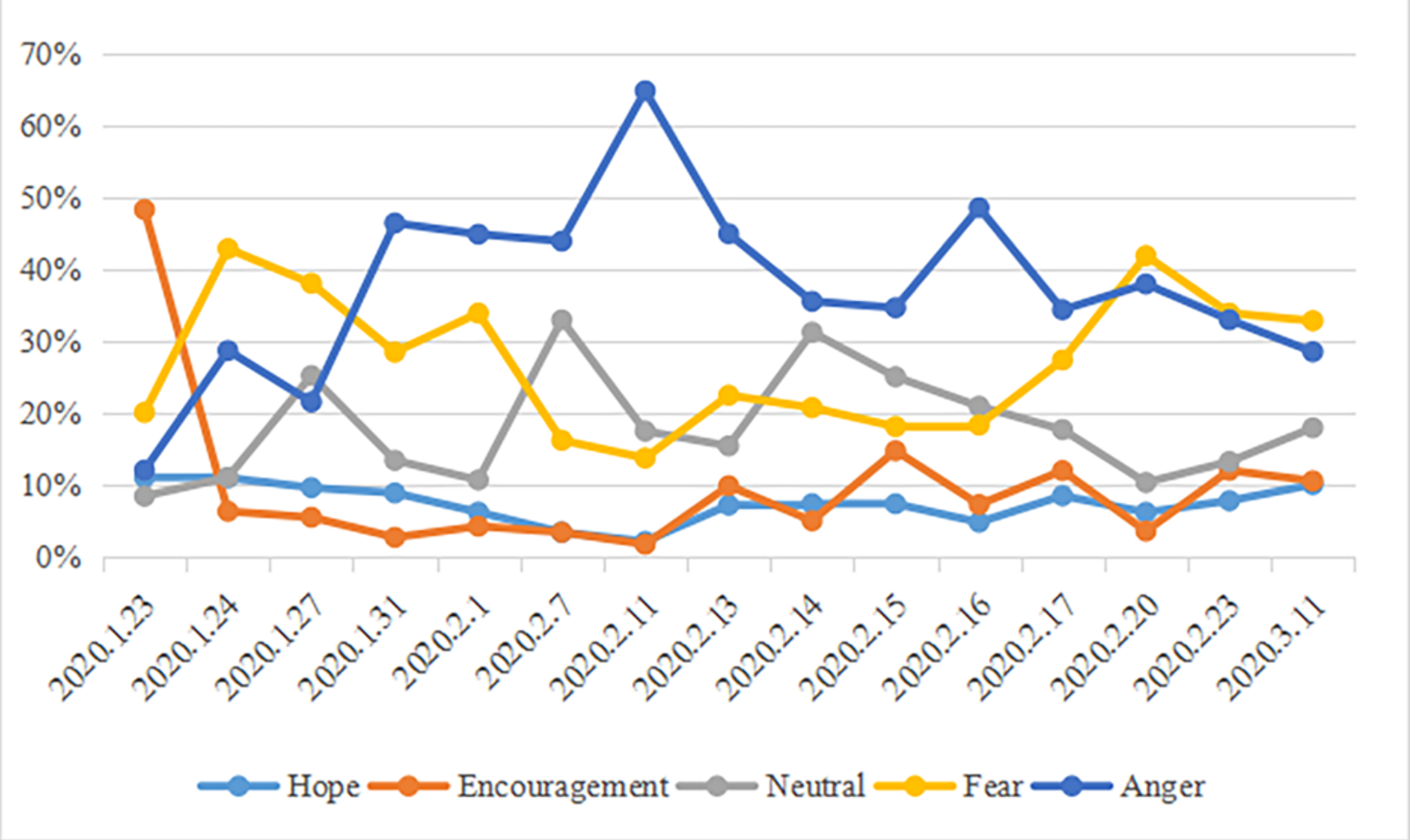


Moderating Effects of Social Distancing Measures on the Influencing Factors of Emotional Polarity

The influence of explanatory variables on the explained variable is shown in Table 5. The reference group of emotional polarity is neutral emotions, and there was no multicollinearity in the data. Older citizens were more inclined to express neutral attitudes. Users in Hubei Province were more likely to express negative emotions, although there was no statistically significant difference in emotional tendency between emigrant provinces and other provinces. Further, users with accounts registered for longer periods of time were inclined to express negative emotions. Similarly, users with more follows and posts were inclined to express positive attitudes, while users with more fans were inclined to express neutral attitudes. Therefore, the explanatory variables do have an impact on the explained variable. Accordingly, hypotheses $\mathrm{H} 1 \mathrm{a}-\mathrm{c}$ and $\mathrm{H} 2 \mathrm{a}-\mathrm{c}$ were supported.

Table 5. Analysis of the influence of explanatory variables on explained variables $(\mathrm{N}=21,395)$.

\begin{tabular}{|c|c|c|}
\hline Variables & Negative, $\mathrm{OR}^{\mathrm{a}}(95 \% \mathrm{CI})$ & Positive, OR (95\% CI) \\
\hline Sex (reference group: male) & $1.18\left(1.05-1.32^{\mathrm{b}}\right)$ & $2.21\left(1.96-2.49^{b}\right)$ \\
\hline Age & $0.99\left(0.98-0.99^{\mathrm{b}}\right)$ & $0.97\left(0.98-0.98^{\mathrm{b}}\right)$ \\
\hline Space0 (reference group) & $-^{c}$ & - \\
\hline Space1 & $1.18\left(1.02-1.38^{\mathrm{b}}\right)$ & $0.52\left(0.44-0.62^{\mathrm{b}}\right)$ \\
\hline Space2 & $1.09(0.97-1.22)$ & $1.10(0.98-1.24)$ \\
\hline Time_Reg $^{\mathrm{d}}$ & $1.02(0.99-1.04)$ & $0.90\left(0.88-0.93^{\mathrm{b}}\right)$ \\
\hline Ln(N_Fan $)^{\mathrm{e}}$ & $0.97(0.94-1.01)$ & $0.98\left(0.94-0.99^{b}\right)$ \\
\hline Ln(N_Follow $)^{\mathrm{f}}$ & $1.01\left(1.02-1.08^{\mathrm{b}}\right)$ & $1.05(0.99-1.12)$ \\
\hline $\operatorname{Ln}(\text { N_Post })^{\mathrm{g}}$ & $0.96\left(0.93-0.99^{\mathrm{b}}\right)$ & $1.06\left(1.03-1.10^{\mathrm{b}}\right)$ \\
\hline SDM $1^{\mathrm{h}}$ & $0.49\left(0.31-0.78^{b}\right)$ & $7.66\left(4.99-11.77^{b}\right)$ \\
\hline $\operatorname{SDM} 2^{\mathrm{i}}$ & $0.46\left(0.28-0.75^{\mathrm{b}}\right)$ & $6.75\left(4.14-11.00^{\mathrm{b}}\right)$ \\
\hline $\mathrm{SDM}^{\mathrm{j}}$ & $0.59\left(0.38-0.92^{\mathrm{b}}\right)$ & $1.08(0.73-1.59)$ \\
\hline $\mathrm{SDM} 4^{\mathrm{k}}$ & $0.92(0.46-1.81)$ & $0.70(0.38-1.28)$ \\
\hline SDM $5^{1}$ & $0.56\left(0.36-0.88^{\mathrm{b}}\right)$ & $8.63\left(5.68-13.11^{\mathrm{b}}\right)$ \\
\hline SDM $^{\mathrm{m}}$ (reference group) & - & - \\
\hline
\end{tabular}

${ }^{\mathrm{a} O R}$ : odds ratio.

${ }^{\mathrm{b}} P<.05$.

${ }^{\mathrm{c}}$ Not applicable.

${ }^{\mathrm{d}}$ Time_Reg: registration year.

${ }^{\mathrm{e}} \mathrm{Ln}$ (N_Fan): logarithm of fan numbers.

${ }_{\mathrm{f}}^{\mathrm{Ln}}$ (N_Follow): logarithm of follow numbers.

${ }^{\mathrm{g}} \mathrm{Ln}$ (N_Post): logarithm of post numbers.

${ }^{\mathrm{h}} \mathrm{SDM} 1$ : delaying the resumption of work and school.

${ }^{\mathrm{i}} \mathrm{SDM} 2$ : travel restrictions.

${ }^{\mathrm{j}} \mathrm{SDM} 3$ : traffic restrictions.

${ }^{\mathrm{k}} \mathrm{SDM} 4$ : closing public spaces.

${ }^{1}$ SDM5: community containment.

${ }^{m}$ SDM6: extending the Lunar New Year holiday.

To examine the effects of the moderating variable on the relationship between users' characteristics and emotions (positive or negative), interactions between social distancing measures and explanatory variables were observed through binary logistic regression analysis. During this process, 64 outliers were removed, based on the residuals analysis, making the results more meaningful. The omnibus tests of model coefficients were statistically significant $\left(\chi_{48}^{2}=4994.56, P<.001\right)$, and the Hosmer-Lemeshow goodness-of-fit was $0.24\left(\chi_{8}^{2}=10.34\right.$, $P>.24)$, indicating that our model has a good goodness of fit. In review of the interaction term results for each social distancing measure of the moderating variable and the explanatory variable, including the odds ratio and 95\% CI, it was found that compared with other social distancing measures, 
some measures had a positive or negative emotion regulation effect on the relationship between the explanatory variable and emotional attitude.

Table 6 summarizes the statistically significant emotional tendency of each explanatory variable under each social distancing measure (for the details of interaction effect, see Multimedia Appendix 1). In general, for these explanatory variables, compared with other types of social distancing measures, the measures of delaying the resumption of work and school (SDM1) or travel restrictions (SDM2) mainly had a positive moderating effect on public emotion, while the measures of traffic restrictions (SDM3) or community containment (SDM5) mainly had a negative moderating effect on public emotion. For the explanatory variable Ln(N_Post), the emotional regulation effects of SDM3 and SDM5 were positive. Different social distancing measures had differing moderating effects on the relationship between user characteristics and user emotions. Therefore, hypothesis H3 is valid.

Table 6. Statistics on the emotional tendency of explanatory variables under the moderating effect of various social measures.

\begin{tabular}{lll}
\hline Variable & $\begin{array}{l}\text { The measures make the explanatory variables have a posi- } \\
\text { tive tendency toward emotions }\end{array}$ & $\begin{array}{l}\text { The measures make the explanatory variables have a nega- } \\
\text { tive tendency toward emotions }\end{array}$ \\
\hline Age & SDM1 $^{\mathrm{a}}, \mathrm{SDM} 2^{\mathrm{b}}, \mathrm{SDM}^{\mathrm{c}}$ & SDM $^{\mathrm{d}}, \mathrm{SDM}^{\mathrm{e}}, \mathrm{SDM}^{\mathrm{f}}$ \\
Space1 & SDM1, SDM2 & SDM3, SDM4, SDM5 \\
Time_Reg & SDM5 \\
Ln(N_Fan $)^{\mathrm{h}}$ & SDM1, SDM2, SDM3, SDM6 & SDM1, SDM3 \\
Ln(N_Follow $)^{\mathrm{i}}$ & SDM2 & SDM2, SDM3 \\
Ln(N_Post $)^{\mathrm{j}}$ & SDM1 & SDM2, SDM6
\end{tabular}

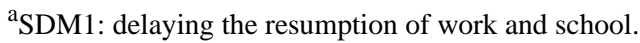

${ }^{\mathrm{b}} \mathrm{SDM} 2$ : travel restrictions.

${ }^{\mathrm{c}} \mathrm{SDM} 3$ : traffic restrictions.

$\mathrm{d}_{\text {SDM4: closing public spaces. }}$

${ }^{\mathrm{e}} \mathrm{SDM}$ 5: community containment.

${ }^{\mathrm{f}}$ SDM6: extending the Lunar New Year holiday.

g Time_Reg: registration year.

$\mathrm{h}_{\mathrm{Ln}}$ (N_Fan): logarithm of fan numbers.

${ }^{i}$ Ln(N_Follow): logarithm of follow numbers.

${ }^{\mathrm{j}} \mathrm{Ln}\left(\mathrm{N} \_\right.$Post): logarithm of post numbers.

\section{Discussion}

In this study, the comments shared by Sina Weibo users related to the social distancing measures imposed by the People's Government of Hubei Province during the COVID-19 pandemic were examined. Machine learning and statistical analysis were used to reveal the emotional attitudes of users toward social distancing measures, as well as the effect of different user characteristics and social distancing measures on the users' emotions, especially the moderating effect of social distancing measures on the relationship between user characteristics and users' emotions.

\section{Sina Weibo Users' Attention to Social Distancing Measures Varied}

Sina Weibo users paid varying attention to the social distancing measures imposed by the People's Government of Hubei Province. The three measures of traffic restrictions, community containment, and delaying resumption of work and school attracted public attention. The main reason for this is that these measures are closely related to the transportation and daily lives of citizens in Hubei Province. When the epidemic situation became more serious, citizens paid greater attention to the daily travel of medical staff and the guaranteeing of living materials for citizens in quarantine. Although the measures of extending the Lunar New Year holiday, travel restrictions, and closing public places are necessary for epidemic prevention and control, they are less relevant to the daily lives of citizens living in Hubei Province. Therefore, these measures were less concerning for users.

In addition, Sina Weibo users in different spatial locations expressed differing levels of attention to social distancing measures imposed in Hubei Province. Users residing in Hubei Province are at the center of the epidemic and felt more deeply about the relevant measures. They are also the group most concerned about social distancing measures. Secondly, for Sina Weibo users in emigrant provinces, such as Guangdong and Beijing, where people in Hubei Province went after the lockdown of Wuhan, these people mainly included students and workers who went to school and work in Hubei Province and, therefore, became worried about the safety of their long-term residence. In particular, Guangdong confirmed the first case of the coronavirus on January 19, 2020, becoming the first province in Mainland China to have a confirmed case of COVID-19 outside of Hubei Province [75]. Sina Weibo users in other provinces paid less attention to Hubei Province since they reside 
far away from the region. Further, results of our emotional polarity analyses show that users from Hubei Province expressed strong negative emotions, while users in emigrant and other provinces expressed stronger positive emotions, indicating that people at the center of the outbreak have strong negative emotions [61]. As for gender, women shared stronger and more positive emotions than men [71].

\section{Sina Weibo Users' Attitudes Toward Social Distancing Measures Were Mainly Negative}

The emotional polarity analysis revealed the attitudes of Sina Weibo users toward the social distancing measures imposed in Hubei Province. The emotional analysis results of the whole corpus showed that the emotions of users were mainly negative, which indicated that although social distancing measures had brought great benefits to the prevention and control of the epidemic in Hubei Province, they still inevitably affected citizens' lives in a negative way [76]. As for the social distancing measures imposed, the measure of traffic restrictions was promulgated at the initial stage of the epidemic, together with the notice of the Wuhan lockdown, with users residing outside of Hubei Province supporting and encouraging this measure. However, after the measure of extending the Lunar New Year holiday was imposed on January 27, 2020, citizens gradually realized the threat to their lives brought on by COVID-19. At the same time, a series of measures had been imposed to disturb citizens daily lives and, therefore, the negative emotions of fear and anger remained high. For example, under the measures of delaying the resumption of work and school and extending the Lunar New Year holiday, citizens began to worry about their studies, job security, and future family income [77]. After the traffic ban was imposed, people worried about travel outside of their homes, especially medical staff. For community containment, people were forced to stay at home, resulting in a reduction in life satisfaction, which led to an increased feeling of loneliness and psychological distress. Further, loneliness, which is likely to be exacerbated through greater fear and confusion, was seen to increase the risk of mental and physical diseases [78]. For this, more remote assistance, such as psychological counseling for families, was needed.

\section{Sina Weibo Users With Different Social Media Characteristics Have Varying Emotional Tendencies}

The results of the logistic regression analysis supported the results of our emotional polarities analysis. Women were indeed more likely to express stronger and more positive emotions. Users in Hubei Province, who were at the center of the epidemic, were more inclined to express negative emotions. For users of different ages, older citizens were inclined to send neutral comments, possibly because younger users do not have enough life experiences to distinguish right from wrong and tend to accept all information without question. This is consistent with the research of Holmes [79], who found that the COVID-19 pandemic had a significant negative impact on social groups, especially young people. In addition, users who had been using Sina Weibo for a longer period of time were more likely to share negative comments, possibly because they have a higher risk perception than those who seldom use social media [80]. Further, users with more fans and follows and those who shared a greater number of posts were inclined to express neutral or positive attitudes. For this result, we understand that users with ample follows can obtain information from multiple sources to identify relatively positive information and disseminate it. Similarly, users with a large number of fans are considered to be somewhat influential in their community [81] and hold an attitude of being responsible to their fans and, therefore, tend to post objective and positive comments to prevent fans from panicking due to excessive processing of information. Therefore, users with many fans can play a guiding role by posting objective facts or words of encouragement, so as to reduce the negative emotions experienced by fans. Social media providers should also give full attention to the role that their platform plays in the lives of citizens, providing comprehensive and accurate information to citizens [82]. They should also send appropriate notifications to prevent negative mental health.

\section{Attention Should Be Paid to the Moderating Effect of Social Distancing Measures}

The moderating effect of social distancing measures on the relationship between different user characteristics and emotions of users varied. In public health emergencies, for all six social distancing measures, the measures of delaying the resumption of work and school or travel restrictions may be met with more acceptance by citizens. Travel restrictions during the epidemic are an inevitable measure, especially since the epidemic occurred during the Lunar New Year holiday. At the time, many residents left Wuhan to travel to see relatives, making the spread of the disease a more serious issue [83]. Tourism is not very important in the face of personal safety, so people are more accepting of travel restrictions. Further, the measures of traffic restrictions or community containment are easily accepted by citizens. The emotion results show that these measures were associated with the most positive emotions; this is because when these measures were first promulgated, people believed their implementation could cut off routes of viral transmission and be effective for epidemic prevention and control. However, continuous traffic restrictions have brought significant inconvenience to citizens' travel plans, especially those related to employment. In response to this situation, government departments should take timely measures to resolve this problem, such as arranging specialized personnel or calling on more volunteers to provide convenience to those who need to travel, so as to alleviate the negative emotions of people. In particular, the measure of community containment is shown to increase health anxiety, financial worry, and loneliness $[84,85]$, and may lead to depression and anxiety among older citizens. For this, governments must take action to strengthen interactions within local communities [86] and provide remote assistance, such as counseling for families, to reduce the psychological burden of citizens.

\section{Implications and Limitations}

This study has a good degree of theoretical value. We explored the relevant characteristics that affect users' emotions from the perspective of the Media Dependence Theory, 5W Theory, and Agenda-Setting Theory, and then analyzed the influence relationship between user characteristics and users' emotions. This study has enriched the research directions of these three 
theories from a new perspective and has created a certain reference value for future studies.

In addition, our results have a degree of practical significance. We found that Sina Weibo users' views and attitudes toward social distancing measures imposed by the People's Government of Hubei Province varied. Users with different characteristics also had different emotional tendencies. In particular, social distancing measures had a moderating effect on the relationship between user characteristics and users' emotions. These results are helpful for government agencies to uncover, in a timely manner, citizens' emotions pertaining to measure implementations. Our findings also provide guidelines for social media platforms to push targeted content to users.

This study has several limitations. First, due to restrictions by Sina Weibo, the secondary comment data below the posts was not obtained, which may affect the results and discussion presented. Second, the training data labels of emotion classifiers were mainly marked manually through the establishment of labeling guidelines. Further, the expression of emotion is highly subjective, and manual labeling may not reflect the real emotions of users adequately. These factors may affect the classification effect of emotional polarity classifiers to a certain extent. Finally, this study only analyzed the emotions in the text without considering emoticons, which may have a certain influence on the results of emotion classification. Future research should consider the effect of emoticons and punctuation on emotional intensity.

\section{Conclusions}

This study combined machine learning and statistical analysis to explore the emotional attitudes of citizens toward social distancing measures imposed by the People's Government of Hubei Province, as well as these emotions' influencing factors. The results of our emotional analysis show that Sina Weibo users have different attitudes toward the six types of social distancing measures implemented, but they are mainly inclined to express negative emotions. In addition, users' emotional attitudes vary across gender and spatial locations. The logistic regression analysis show that users of different ages, spatial locations, account registration year, number of fans, number of follows, and number of posts have different attitudes toward the imposed social distancing measures. Most importantly, this study found that social distancing measures have a moderating effect on the relationship between different user characteristics and users' emotions. The results obtained allow government agencies to better understand the views of citizens toward related events and can help government agencies take timely actions to alleviate negative emotions during public health emergencies.

\section{Acknowledgments}

This study was supported by the Fundamental Research Funds for the Central Universities, HUST (\#2019WKYXZX011). The authors would like to thank all anonymous reviewers for their valuable comments and input on this research.

\section{Authors' Contributions}

RY, the co-first author, designed the study and contributed to data collection and the writing of the manuscript. LS, the co-first author and corresponding author, designed and conducted the study and finalized the manuscript draft. WZ contributed to the discussion and writing of the manuscript draft. RE contributed to the writing of the manuscript and final proofreading. GC contributed to the writing of the manuscript draft. ZZ contributed to the statistical analysis. All authors contributed to the preparation and approval of the final accepted version.

\section{Conflicts of Interest}

None declared.

\section{Multimedia Appendix 1}

The interaction effect of the social distancing measures and explanatory variables.

[DOC File, 209 KB-Multimedia Appendix 1]

\section{References}

1. The voice of the war epidemic - National Health Commission talks about the new crown pneumonia epidemic-major public health emergency since the founding of New China. China Central Television. 2020 Feb 28. URL: http://tv.cctv.com/2020/ 02/28/VIDE0JG9u43VKoQ4dVUAQWQh200228.shtml [accessed 2021-01-02]

2. Pan SL, Cui M, Qian J. Information resource orchestration during the COVID-19 pandemic: A study of community lockdowns in China. Int J Inf Manage 2020 Oct;54:102143 [FREE Full text] [doi: 10.1016/j.ijinfomgt.2020.102143] [Medline: 32394997]

3. Chen S, Yang J, Yang W, Wang C, Bärnighausen T. COVID-19 control in China during mass population movements at New Year. The Lancet 2020 Mar 07;395(10226):764-766 [FREE Full text] [doi: 10.1016/S0140-6736(20)30421-9] [Medline: 32105609]

4. Fong MW, Gao H, Wong JY, Xiao J, Shiu EYC, Ryu S, et al. Nonpharmaceutical Measures for Pandemic Influenza in Nonhealthcare Settings-Social Distancing Measures. Emerg Infect Dis 2020 May;26(5):976-984 [FREE Full text] [doi: 10.3201/eid2605.190995] [Medline: 32027585] 
5. Wuhan novel coronavirus infection prevention and control command announcement (No. 1). China Government Network. 2020 Jan 23. URL: http://www.gov.cn/xinwen/2020-01/23/content 5471751.htm [accessed 2021-01-02]

6. Notice of novel coronavirus pneumonia epidemic prevention and control headquarters in Hubei Province. People's Government of Hubei Province. 2020. URL: https://baijiahao.baidu.com/s?id=1658419579329417941\&wfr=spider\&for=pc [accessed 2021-01-02]

7. Notice of the General Office of the Hubei Provincial People's Government on extending the Spring Festival Holiday in 2020. People's Government of Hubei Province. 2020. URL: https://baijiahao.baidu.com/

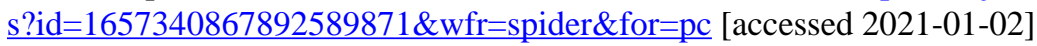

8. Notice on doing a good job in responding to pneumonia caused by new coronavirus infection. Hubei Department of Culture and Tourism. 2020 Jan 30. URL: http://wlt.hubei.gov.cn/bmdt/ztzl/xxgzbd/202001/t20200130_2016384.shtml [accessed 2021-01-02]

9. Notice by the People's Government of Hubei Province on further strengthening COVID-19 prevention and control. People's Government of Hubei Province. 2020. URL: https://baijiahao.baidu.com/s?id=1658701503675498305\&wfr=spider\&for=pc [accessed 2021-01-02]

10. Caley P, Philp DJ, McCracken K. Quantifying social distancing arising from pandemic influenza. J R Soc Interface 2008 Jun 6;5(23):631-639 [FREE Full text] [doi: 10.1098/rsif.2007.1197] [Medline: 17916550]

11. Social distancing: What is social distancing? Centers for Disease Control and Prevention. 2020 Nov 17. URL: https://www. cdc.gov/coronavirus/2019-ncov/prevent-getting-sick/social-distancing.html [accessed 2021-01-02]

12. Global digital population as of October 2020. Statista. 2020 Oct. URL: https://www.statista.com/statistics/617136/ digital-population-worldwide/ [accessed 2021-01-02]

13. The 46th China Statistical Report on Internet Development. China Internet Network Information Center. 2020 Sep. URL: http://www.cnnic.net.cn/hlwfzyj/hlwxzbg/hlwtjbg/202009/P020200929546215182514.pdf [accessed 2021-01-02]

14. Chew C, Eysenbach G. Pandemics in the age of Twitter: content analysis of Tweets during the 2009 H1N1 outbreak. PLoS One 2010 Nov 29;5(11):e14118 [FREE Full text] [doi: 10.1371/journal.pone.0014118] [Medline: 21124761]

15. Sina Weibo. URL: http://weibo.com/ [accessed 2021-01-02]

16. Chen Z, Su K. Research on the media role of Weibo in public health emergencies — take the 'novel coronavirus pneumonia' as an example. Today's Mass Media 2020 May 5;28(5):12-15 [FREE Full text]

17. Giunti G, Claes M, Dorronzoro Zubiete E, Rivera-Romero O, Gabarron E. Analysing Sentiment and Topics Related to Multiple Sclerosis on Twitter. Stud Health Technol Inform 2020 Jun 16;270:911-915. [doi: 10.3233/SHTI200294] [Medline: $\underline{32570514]}$

18. Bai H, Yu G. A Weibo-based approach to disaster informatics: incidents monitor in post-disaster situation via Weibo text negative sentiment analysis. Nat Hazards 2016 May 30;83(2):1177-1196. [doi: 10.1007/s11069-016-2370-5]

19. Hatchett RJ, Mecher CE, Lipsitch M. Public health interventions and epidemic intensity during the 1918 influenza pandemic. Proc Natl Acad Sci U S A 2007 May 01;104(18):7582-7587 [FREE Full text] [doi: 10.1073/pnas.0610941104] [Medline: 17416679]

20. Flu pandemic study supports social distancing. National Institutes of Health. 2011 Jun 6. URL: https://www.nih.gov/ news-events/nih-research-matters/flu-pandemic-study-supports-social-distancing [accessed 2021-01-02]

21. Bondy SJ, Russell ML, Laflèche JM, Rea E. Quantifying the impact of community quarantine on SARS transmission in Ontario: estimation of secondary case count difference and number needed to quarantine. BMC Public Health 2009 Dec 24;9:488 [FREE Full text] [doi: 10.1186/1471-2458-9-488] [Medline: 20034405]

22. Zhang J, Litvinova M, Liang Y, Wang Y, Wang W, Zhao S, et al. Changes in contact patterns shape the dynamics of the COVID-19 outbreak in China. Science 2020 Jun 26;368(6498):1481-1486 [FREE Full text] [doi: 10.1126/science.abb8001] [Medline: 32350060 ]

23. Brown ST, Tai JHY, Bailey RR, Cooley PC, Wheaton WD, Potter MA, et al. Would school closure for the 2009 H1N1 influenza epidemic have been worth the cost?: a computational simulation of Pennsylvania. BMC Public Health 2011 May 20;11:353 [FREE Full text] [doi: 10.1186/1471-2458-11-353] [Medline: 21599920]

24. Milne GJ, Kelso JK, Kelly HA, Huband ST, McVernon J. A small community model for the transmission of infectious diseases: comparison of school closure as an intervention in individual-based models of an influenza pandemic. PLoS One 2008;3(12):e4005 [FREE Full text] [doi: 10.1371/journal.pone.0004005] [Medline: 19104659]

25. Chin TDY, Foley JF, Doto IL, Gravelle CR, Weston J. Morbidity and mortality characteristics of Asian strain influenza. Public Health Rep 1960 Feb;75(2):149-158 [FREE Full text] [Medline: 19316351]

26. Teh B, Olsen K, Black J, Cheng AC, Aboltins C, Bull K, et al. Impact of swine influenza and quarantine measures on patients and households during the H1N1/09 pandemic. Scand J Infect Dis 2012 Apr;44(4):289-296. [doi: 10.3109/00365548.2011.631572] [Medline: 22106922]

27. Tan C. SARS in Singapore--key lessons from an epidemic. Ann Acad Med Singap 2006 May;35(5):345-349 [FREE Full text] [Medline: 16830002$]$

28. Hoffmann RK, Hoffmann K. Ethical considerations in the use of cordons sanitaires. Clinical Correlations. 2015 Feb 19. URL: https://www.clinicalcorrelations.org/2015/02/19/ethical-considerations-in-the-use-of-cordons-sanitaires/ [accessed 2021-01-02] 
29. Ahmed F, Zviedrite N, Uzicanin A. Effectiveness of workplace social distancing measures in reducing influenza transmission: a systematic review. BMC Public Health 2018 Apr 18;18(1):518 [FREE Full text] [doi: 10.1186/s12889-018-5446-1] [Medline: 29669545]

30. Chinazzi M, Davis JT, Ajelli M, Gioannini C, Litvinova M, Merler S, et al. The effect of travel restrictions on the spread of the 2019 novel coronavirus (COVID-19) outbreak. Science 2020 Apr 24;368(6489):395-400 [FREE Full text] [doi: 10.1126/science.aba9757] [Medline: 32144116]

31. Islam N, Sharp SJ, Chowell G, Shabnam S, Kawachi I, Lacey B, et al. Physical distancing interventions and incidence of coronavirus disease 2019: natural experiment in 149 countries. BMJ 2020 Jul 15;370:m2743 [FREE Full text] [doi: 10.1136/bmj.m2743] [Medline: 32669358$]$

32. Ao B. Social distancing can strain mental health. The Philadelphia Inquirer. 2020 Mar 19. URL: https://www.inquirer.com/ health/coronavirus/coronavirus-mental-health-social-distancing-20200319.html [accessed 2021-01-02]

33. Cao W, Fang Z, Hou G, Han M, Xu X, Dong J, et al. The psychological impact of the COVID-19 epidemic on college students in China. Psychiatry Res 2020 May;287:112934 [FREE Full text] [doi: 10.1016/j.psychres.2020.112934] [Medline: $\underline{32229390]}$

34. Chen HY, Wang JP, Xie W, Chen W. A study of Internet user's mood and its relevant variables under the crisis of SARS. Chinese Journal of Applied Psychology 2003 Dec 30(4):7-13. [doi: 10.3969/j.issn.1006-6020.2003.04.002]

35. Qian M, Ye D, Dong W, Huang Z, Zhang L, Liu X. Behaviour, cognition and emotion of the public in Beijing towards SARS. Chinese Mental Health Journal 2003 Aug 15(8):515-520. [doi: 10.3321/j.issn:1000-6729.2003.08.001]

36. Ogoina D, Oyeyemi AS, Ayah O, Onabor A, Midia A, Olomo WT, et al. Preparation and Response to the 2014 Ebola Virus Disease Epidemic in Nigeria-The Experience of a Tertiary Hospital in Nigeria. PLoS One 2016 Oct 27;11(10):e0165271 [FREE Full text] [doi: 10.1371/journal.pone.0165271] [Medline: 27788191]

37. Khalid I, Khalid TJ, Qabajah MR, Barnard AG, Qushmaq IA. Healthcare Workers Emotions, Perceived Stressors and Coping Strategies During a MERS-CoV Outbreak. Clin Med Res 2016 Mar;14(1):7-14 [FREE Full text] [doi: 10.3121/cmr.2016.1303] [Medline: 26847480]

38. Jiao WY, Wang LN, Liu J, Fang SF, Jiao FY, Pettoello-Mantovani M, et al. Behavioral and Emotional Disorders in Children during the COVID-19 Epidemic. J Pediatr 2020 Jun;221:264-266.e1 [FREE Full text] [doi: 10.1016/j.jpeds.2020.03.013] [Medline: 32248989]

39. Baccianella S, Esuli A, Sebastiani F. SentiWordNet 3.0: an enhanced lexical resource for sentiment analysis and opinion mining. 2010 Presented at: The 2010 International Conference on Language Resources and Evaluation; May 17-23; Valletta, Malta URL: https://www.aclweb.org/anthology/L10-1531/

40. Mohammad S, Turney P. Crowdsourcing a word-emotion association lexicon. Comput Intell 2012;29(3):436-465. [doi: 10.1111/j.1467-8640.2012.00460.x]

41. Das S, Dutta A. Characterizing public emotions and sentiments in COVID-19 environment: A case study of India. J Hum Behav Soc Environ 2020 Jul 14:1-14. [doi: 10.1080/10911359.2020.1781015]

42. Du J, Tang L, Xiang Y, Zhi D, Xu J, Song H, et al. Public Perception Analysis of Tweets During the 2015 Measles Outbreak: Comparative Study Using Convolutional Neural Network Models. J Med Internet Res 2018 Jul 09;20(7):e236 [FREE Full text] [doi: 10.2196/jmir.9413] [Medline: 29986843]

43. Ji X, Chun S, Geller J. Monitoring public health concerns using Twitter sentiment classifications. 2013 Presented at: The 2013 IEEE International Conference on Healthcare Informatics; Sept 9-11; Philadelphia, PA p. 335-344 URL: https:/ /ieeexplore.ieee.org/abstract/document/6680494 [doi: 10.1109/ichi.2013.47]

44. Pondora Naresh Behera, Suneetha Eluri. Analysis of Public Health Concerns using Two-step Sentiment Classification. IJERT 2015 Sep 24;V4(09):606-610. [doi: 10.17577/ijertv4is090641]

45. Notice of the People's Government of Hubei Province on strengthening the prevention and control work of novel Coronavirus infection. People's Government of Hubei Province. 2020 Jan 21. URL: http://www.hubei.gov.cn/zfwj/ezf/202002/ t20200220 2142431.shtml [accessed 2021-01-02]

46. Hu CL, Tang JT, Wang T. Topical relevance analysis of hashtags in Chinese microblogging environment. Computer Science 2013 Nov 15;40(S2):235-237. [doi: 10.3969/j.issn.1002-137X.2013.z2.058]

47. Pang B, Lee L. Opinion Mining and Sentiment Analysis. Ithaca, NY: Foundations and Trends in Information Retrieval; 2008.

48. Mukhtar N, Khan MA, Chiragh N. Lexicon-based approach outperforms Supervised Machine Learning approach for Urdu Sentiment Analysis in multiple domains. Telematics and Informatics 2018 Dec;35(8):2173-2183. [doi: 10.1016/j.tele.2018.08.003]

49. Shrestha H, Dhasarathan C, Munisamy S, Jayavel A. Natural Language Processing Based Sentimental Analysis of Hindi (SAH) Script an Optimization Approach. Int J Speech Technol 2020 Jul 09;23(4):757-766. [doi: 10.1007/s10772-020-09730-x]

50. Kumar A, Srinivasan K, Cheng W, Zomaya AY. Hybrid context enriched deep learning model for fine-grained sentiment analysis in textual and visual semiotic modality social data. Information Processing \& Management 2020 Jan;57(1):102141. [doi: 10.1016/j.ipm.2019.102141]

51. Ortony A, Clore G, Collins A. The Cognitive Structure of Emotions. New York, NY: Cambridge University Press; 1988. 
52. Wu P, Li X, Shen S, He D. Social media opinion summarization using emotion cognition and convolutional neural networks. Int J Inf Manage 2020 Apr;51:101978. [doi: 10.1016/j.ijinfomgt.2019.07.004]

53. Xia F, Yetisgen-Yildiz M. Clinical corpus annotation: challenges and strategies. 2012 Presented at: The Third Workshop on Building and Evaluating Resources for Biomedical Text Mining; May 26; Istanbul, Turkey URL: http://www.nactem.ac.uk/ biotxtm2012/presentations/Yetisgen-Yildiz-pres.pdf

54. Carletta J. Assessing agreement on classification tasks: the kappa statistic. Comput Linguist 1996 Jun;22:249-254 [FREE Full text]

55. Rigby AS. Statistical methods in epidemiology. v. Towards an understanding of the kappa coefficient. Disabil Rehabil 2000 May 20;22(8):339-344. [doi: 10.1080/096382800296575] [Medline: $\underline{10896093}$ ]

56. Hu J. Automated Detection of Driver Fatigue Based on AdaBoost Classifier with EEG Signals. Front Comput Neurosci 2017 Aug 3;11:72 [FREE Full text] [doi: 10.3389/fncom.2017.00072] [Medline: 28824409]

57. Bi Q, Shen L, Evans R, Zhang Z, Wang S, Dai W, et al. Determining the Topic Evolution and Sentiment Polarity for Albinism in a Chinese Online Health Community: Machine Learning and Social Network Analysis. JMIR Med Inform 2020 May 29;8(5):e17813 [FREE Full text] [doi: 10.2196/17813] [Medline: $\underline{\text { 32469320] }}$

58. Ball-Rokeach SJ. The origins of individual media system dependency: a sociological framework. Communication Research 2016 Jun 30;12(4):485-510. [doi: 10.1177/009365085012004003]

59. Wu B. Research on Microblog Emotional Expression Based on Media System Dependence Perspective—Taking "Hangzhou Nanny Arson" as an Example. ASS 2018;07(10):1693-1701. [doi: 10.12677/ass.2018.710253]

60. de Souza LC, Bertoux M, de Faria ÂRV, Corgosinho LTS, Prado ACDA, Barbosa IG, et al. The effects of gender, age, schooling, and cultural background on the identification of facial emotions: a transcultural study. Int Psychogeriatr 2018 Dec;30(12):1861-1870. [doi: 10.1017/S1041610218000443] [Medline: 29798733]

61. van Lent LG, Sungur H, Kunneman FA, van de Velde B, Das E. Too Far to Care? Measuring Public Attention and Fear for Ebola Using Twitter. J Med Internet Res 2017 Dec 13;19(6):e193 [FREE Full text] [doi: 10.2196/jmir.7219] [Medline: 28611015]

62. Griffin RJ, Dunwoody S, Neuwirth K. Proposed model of the relationship of risk information seeking and processing to the development of preventive behaviors. Environ Res 1999 Feb;80(2 Pt 2):S230-S245. [doi: 10.1006/enrs.1998.3940] [Medline: 10092438]

63. Yang ZJ, Aloe AM, Feeley TH. Risk Information Seeking and Processing Model: A Meta-Analysis. J Commun 2014 Jan 07;64(1):20-41. [doi: 10.1111/jcom.12071]

64. Lasswell HD. The structure and function of communication in society. In: Bryson L, editor. The Communication of Ideas. New York, NY: Harper and Row; 1948:37-51.

65. Liao HH, Wang YF. Public opinion dissemination over social media: case study of Sina Weibo and 8/12 Tianjin explosion. Data Analysis and Knowledge Discovery 2016 Dec 25:12-93 [FREE Full text]

66. Chen J, Liu YP, Deng SL. Research on user reviews of government rumor-refuting information and factors influencing their emotional tendencies. Information Science 2017 Dec 5;35(12):61-65. [doi: 10.13833/j.issn.1007-7634.2017.12.011]

67. Lin C. Analysis on evaluation indexes of information dissemination impact of micro-blog Individual. Library and Information Service 2014 Feb 25;58(1):40-43. [doi: 10.13266/j.issn.0252-3116.2014.01.006]

68. McCombs M, Shaw D. The agenda-setting function of mass media. Public Opinion Quarterly 1972 Jan 1;36(2):176-187. [doi: $10.1086 / 267990]$

69. McCombs ME, Shaw DL, Weaver DH. New Directions in Agenda-Setting Theory and Research. Mass Communication and Society 2014 Nov 24;17(6):781-802. [doi: 10.1080/15205436.2014.964871]

70. Vargo CJ, Guo L, McCombs M, Shaw DL. Network Issue Agendas on Twitter During the 2012 U.S. Presidential Election. J Commun 2014 Mar 24;64(2):296-316. [doi: 10.1111/jcom.12089]

71. Kucuktunc O, Cambazoglu B, Weber I, Ferhatosmanoglu H. A large-scale sentiment analysis for Yahoo! Answers. 2012 Feb Presented at: Proceedings of the Fifth ACM International Conference on Web Search and Data Mining; Feb 8-12; Seattle, WA p. 633-642. [doi: 10.1145/2124295.2124371]

72. Popular places to relocate during the Spring Festival travel season (destination). Baidu Migration. URL: http://qianxi. baidu.com/ [accessed 2021-01-02]

73. Chen Z, Zhang Q, Lu Y, Guo Z, Zhang X, Zhang W, et al. Distribution of the COVID-19 epidemic and correlation with population emigration from Wuhan, China. Chin Med J (Engl) 2020 May 05;133(9):1044-1050 [FREE Full text] [doi: 10.1097/CM9.0000000000000782] [Medline: 32118644]

74. Jaccard J. Interaction effects in logistic regression, 1st edition. London, UK: Sage Publications, Inc; 2001.

75. Jiang Y. The National Health Commission confirmed the first confirmed case of novel coronavirus infection in Guangdong province. China News. 2020 Jan 20. URL: http://www.chinanews.com/sh/2020/01-20/9064733.shtml [accessed 2021-01-02]

76. Thu TPB, Ngoc PNH, Hai NM, Tuan LA. Effect of the social distancing measures on the spread of COVID-19 in 10 highly infected countries. Sci Total Environ 2020 Nov 10;742:140430 [FREE Full text] [doi: 10.1016/j.scitotenv.2020.140430] [Medline: 32623158]

77. Baum NM, Jacobson PD, Goold SD. "Listen to the people": public deliberation about social distancing measures in a pandemic. Am J Bioeth 2009 Nov;9(11):4-14. [doi: 10.1080/15265160903197531] [Medline: 19882444] 
78. Beutel ME, Klein EM, Brähler E, Reiner I, Jünger C, Michal M, et al. Loneliness in the general population: prevalence, determinants and relations to mental health. BMC Psychiatry 2017 Mar 20;17(1):97 [FREE Full text] [doi: 10.1186/s12888-017-1262-x] [Medline: 28320380]

79. Holmes EA, O'Connor RC, Perry VH, Tracey I, Wessely S, Arseneault L, et al. Multidisciplinary research priorities for the COVID-19 pandemic: a call for action for mental health science. The Lancet Psychiatry 2020 Jun 15;7(6):547-560 [FREE Full text] [doi: 10.1016/S2215-0366(20)30168-1] [Medline: 32304649]

80. Ju Y, You M. The Outrage Effect of Personal Stake, Dread, and Moral Nature on Fine Dust Risk Perception Moderated by Media Use. Health Commun 2020 Feb 05:1-11. [doi: 10.1080/10410236.2020.1723046] [Medline: $\underline{32024391]}$

81. Kwak H, Lee C, Park H, Moon S. What is Twitter, a social network or a news media? 2010 Presented at: Proceedings of the 19th International World Wide Web Conference; Apr 26-30; Raleigh, NC p. 591-600. [doi: 10.1145/1772690.1772751]

82. Sadah SA, Shahbazi M, Wiley MT, Hristidis V. Demographic-Based Content Analysis of Web-Based Health-Related Social Media. J Med Internet Res 2016 Jun 13;18(6):e148 [FREE Full text] [doi: 10.2196/jmir.5327] [Medline: 27296242]

83. Kraemer MUG, Yang C, Gutierrez B, Wu C, Klein B, Pigott DM, Open COVID-19 Data Working Group, et al. The effect of human mobility and control measures on the COVID-19 epidemic in China. Science 2020 May 01;368(6490):493-497 [FREE Full text] [doi: 10.1126/science.abb4218] [Medline: 32213647]

84. González-Sanguino C, Ausín B, Castellanos MA, Saiz J, López-Gómez A, Ugidos C, et al. Mental health consequences during the initial stage of the 2020 Coronavirus pandemic (COVID-19) in Spain. Brain Behav Immun 2020 Jul;87:172-176 [FREE Full text] [doi: 10.1016/j.bbi.2020.05.040] [Medline: 32405150]

85. Tull MT, Edmonds KA, Scamaldo KM, Richmond JR, Rose JP, Gratz KL. Psychological Outcomes Associated with Stay-at-Home Orders and the Perceived Impact of COVID-19 on Daily Life. Psychiatry Res 2020 Jul 12;289:113098 [FREE Full text] [doi: 10.1016/j.psychres.2020.113098] [Medline: 32434092]

86. Block P, Hoffman M, Raabe IJ, Dowd JB, Rahal C, Kashyap R, et al. Social network-based distancing strategies to flatten the COVID-19 curve in a post-lockdown world. Nat Hum Behav 2020 Jun;4(6):588-596. [doi: 10.1038/s41562-020-0898-6] [Medline: $\underline{\text { 32499576] }}$
Abbreviations
Bi-LSTM: bi-directional long short-term
CNN: convolutional neural network
LSTM: long short-term memory
NB: naive Bayes
NRC: National Research Council of Canada
OCC: Ortony-Clore-Collins model
RQ: research question
SARS: severe acute respiratory syndrome
SVM: support vector machine

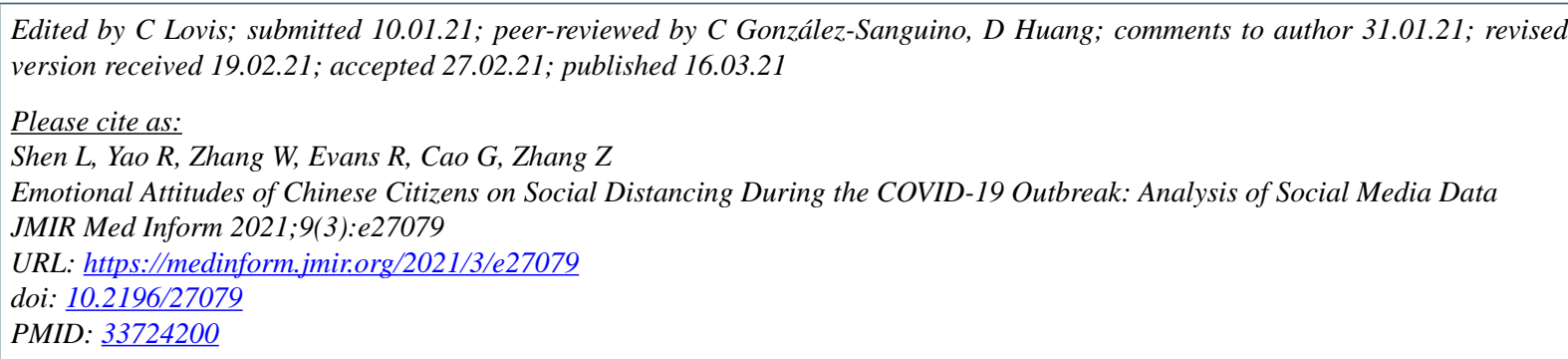

CLining Shen, Rui Yao, Wenli Zhang, Richard Evans, Guang Cao, Zhiguo Zhang. Originally published in JMIR Medical Informatics (http://medinform.jmir.org), 16.03.2021. This is an open-access article distributed under the terms of the Creative Commons Attribution License (https://creativecommons.org/licenses/by/4.0/), which permits unrestricted use, distribution, and reproduction in any medium, provided the original work, first published in JMIR Medical Informatics, is properly cited. The complete bibliographic information, a link to the original publication on http://medinform.jmir.org/, as well as this copyright and license information must be included. 